\title{
A method for dealing with regional differences in population size when interpreting slopes in Google Trends query data.
}

\author{
Malcolm L. McCallum \\ School of Agriculture and Applied Sciences \\ Langston University, Langston, OK 73050 \\ email: malcolm.mccallum.tamut@gmail.com
}

\begin{abstract}
A quandary exists when comparing trend lines of Google Trends query data among different countries. This approach provides directionality and speed of change, but it does not account for the quantity of movement occurring when comparing large regions to small ones. This study applies the physical concept of momentum to the analysis of Google Trends results to provide a method for comparing trends among countries. By accounting for the volume of interest along with the direction and rate of interest gain/loss, one is able to make accurate quantitative statements about how the public in differently sized regions may shift interests and opinion on different issues. Momentum allows us to identify how countries have responded and how they may respond in the future without the erroneous assumption that the behaviors of large and small populations are equally flexible and responsive to new ideas.
\end{abstract}

\section{Introduction}

Google Trends is a free online application that provides access to search query data from the Google database (Choi and Varian 2012). Search queries are important indicators of variation and trends in public interest (Carneiro and Mylonakis 2009; Ripberger 2011), a key influence on how governmental policies are instituted (Monroe et al. 2015; McCallum and Bury 2014, Melon 2013, 2014). People generally enter terms into Google because they are interested in something about them (Baram-Tsabari and Segev 2011; Margetts 2012; Vayena et al. 2012), and Google search volume is strongly correlated with public participation in political issues (Reilly et al. 2012). Google Trends is a flexible, robust data mining tool (Scheitle 2011; Black 2012; Yang 2012) that consistently gives more statistically accurate data than other survey-based indicators of public opinion and interest (Schmidt and Vosen 2011; Ripberger 2011; Kulkarni 2012).

Generally, if a trend in a geographical region has a positive slope over time, interest is growing; and if it is negative, then interest is declining (Seifter et al. 2010; Choi and Varian 2012; McCallum and Bury 2014). Frequently, investigators refer to trends in a colloquial fashion as having momentum. They might say, "Public interest in <fill in blank $>$ has gained momentum." Here, the author implies that interest levels are growing and it might be difficult for that trajectory to change. However, a quantitative approach to the true momentum of public interest is lacking. Understanding the role of true momentum in trends can provide a vitally important understanding of shifting query behavior that is required when comparing results among different geographical regions. This is not unlike the difference between a semi-truck and a bicycle going down a $10 \%$ grade. The bicycle can be stopped with much less effort than the truck. Likewise, public interest/opinion in a large mass of people clearly changes slower than in a smaller group (Dennis 1993; Ridgeway and Balkwell 1997; Ambrus et al. 2009), although social identity can influence those processes (Brewer and Kramer 1986). This is important because public policy at any level of government is determined by the combined influence of public interest and opinion in many individual jurisdictions (Downs 1957; Davis et al. 1970; Page and Shapiro 1983), although well-organized obstructionist groups can counter this phenomenon (Downs 1957; Schattschneider 1960; McConnel 1966). Momentum is a reason why we had the "Great Compromise" in the formation of a House of Representatives and a Senate in United States government (Tindall and Shi 2016). That compromise was to combat momentum in highly populated regions that could dominate policy decisions leading to the suppression or ignorance of smaller jurisdictions. The same phenomenon occurs when comparing Google Trends data among regions. Currently, Google Trends data are compared via slopes and changes in trajectory of scaled relative search volume. This is adequate when restricting a study to a single geographic region; however, it is insufficient when comparing multiple regions because the approach ignores influences caused by variation in their population sizes. A more robust and informative comparison arises by applying the concept of momentum to these data, especially when comparing countries with drastically different populations.

In Physics, momentum is a physical law that demonstrates how mass and velocity (rate) influence the forward movement of an object and is represented by the formula

$$
\mathrm{p}=\operatorname{mv}(\text { Eq. 1) }
$$


where $\mathrm{p}$ is the momentum of the system studied, $\mathrm{m}=$ the mass of the experimental unit, and $\mathrm{v}$ is its angular velocity with which its movement changes (Newton 1687). This mathematical relationship may be applied to Google Trends data by substituting the population of internet users or total population in a given region for "mass." The slope of the plotted data trend is the rate or velocity of the trend and substitutes for "v." This provides a mathematical outcome that relates the size of the population and rate to the momentum of a trend following logical relationships of observed internet activity. Consequently, this relationship allows comparison of the contributions of differently sized political districts on country- or state-wide policy outcomes. By applying this concept, we not only understand differences in public interest (and possibly opinion), but also how strongly a given region's interest might play a role in policy and how difficult this might be to change relative to other political geographies.

Herein, I present the application of the Law of Momentum to internet query data to deal with variable population sizes. I also present a demonstration of its use and interpretation when addressing questions related to public interest.

\section{Materials and Methods}

Google Trends data from 10 randomly chosen European countries were downloaded for a series of the seven most robust environmental terms previously identified as indicator terms of public interest in the environment (McCallum and Bury 2013; 2014; Andrew et al. 2016). Then, I added Montenegro to this data set to compare the former results to a European country with a very small total population and low fraction of internet users. The number of internet users in each country was obtained from http://www.internetlivestats.com/internet-users-by-country/ (last accessed 3-20-2018) and the total population for each country was retrieved from the United Nations 2017 revision of the World Population Prospects (available at: https://esa.un.org, last accessed 3/20/2018). The momentum of public interest in each term for a given country was calculated. Then, I calculated the mean momentum from the individual term's momenta to represent the overall momentum of public interest in the environment for each given country. The momenta and slopes among countries were compared using an Analysis of Variance (ANOVA) and a Tukey means comparisons test.

\section{Results}

None of these countries demonstrate large slopes in their trend lines. The average slope among all countries was 0.011 ( $\mathrm{SE}=0.006)$ search units/mo from $2004-2017$ (Appendix). There were significant differences in slope among these countries (Table 1). Montenegro (Mean Slope $=-0.053$ search units $/ \mathrm{mo}, \mathrm{SE}=0.02$ ) had a steeper decline in interest from 2004 to 2018 than did Bosnia-Herzegovina (Mean Slope $=-0.015$ search units $/ \mathrm{mo}, \mathrm{SE}=$ 0.012; Tukey $=0.009,0.130$ ), Denmark (Mean Slope $=0.008$ search units $/ \mathrm{mo}, \mathrm{SE}=0.011$, Tukey $=0.001,0.122$ ), or Finland (Mean Slope $=0.013$ search units $/ \mathrm{mo}, \mathrm{SE}=0.015$; Tukey $=0.006,0.127$ ). Under graphical examination (Fig. 1), The slope for Montenegro appeared steeper, but several search terms had insufficient search volume to return results (a Google Trends limitation, see McCallum and Bury 2014), thus increasing the influence of those terms for which results were accessible. There were no other differences in the slope of the data distributions among other paired responses.

Table 1. Analysis of Variance for differences in public interest in the environment among 11 European countries.

\begin{tabular}{|c|c|c|c|c|c|}
\hline Source & Df & SS & MS & $\mathbf{F}$ & $\mathbf{P}$ \\
\hline Country & 10 & $4.2 \times 10^{12}$ & $4.20 \times 10^{11}$ & 1.07 & 0.397 \\
\hline Error & 66 & $2.59 \times 10^{13}$ & $3.92 \times 10^{11}$ & & \\
\hline Total & 76 & $3.01 \times 10^{13}$ & & & \\
\hline \multicolumn{6}{|c|}{ ANOVA momentum using $\mathrm{m}=$ internet users } \\
\hline Source & Df & SS & MS & $\mathbf{F}$ & $\mathbf{P}$ \\
\hline Country & 10 & $2.87 \times 10^{12}$ & $2.87 \times 10^{11}$ & 1.03 & 0.428 \\
\hline Error & 66 & $1.84 \times 10^{13}$ & $2.79 \times 10^{11}$ & & \\
\hline Total & 76 & $2.12 \times 10^{13}$ & & & \\
\hline \multicolumn{6}{|c|}{ ANOVA for slope } \\
\hline Source & Df & SS & MS & $\mathbf{F}$ & $\mathbf{P}$ \\
\hline Country & 10 & 0.019 & 0.002 & 2.22 & 0.028 \\
\hline Error & 61 & 0.051 & 0.001 & & \\
\hline Total & 71 & 0.070 & & & \\
\hline
\end{tabular}


A)

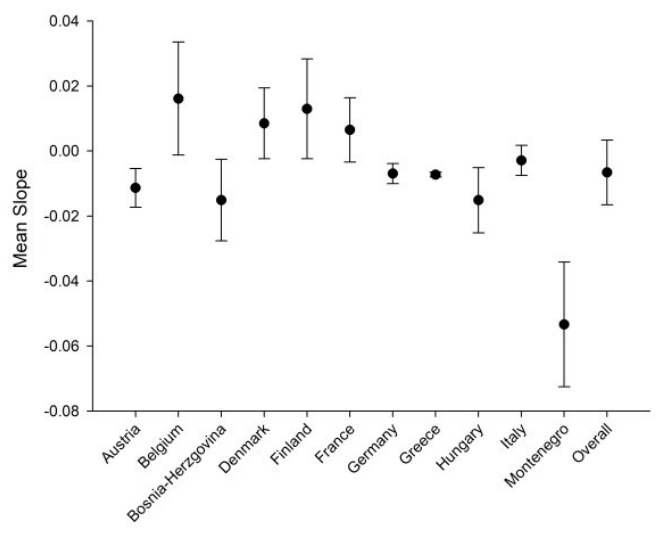

B)

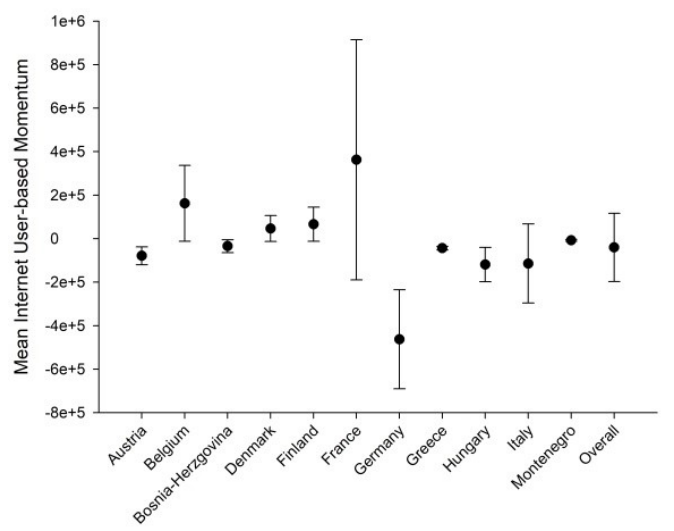

C)

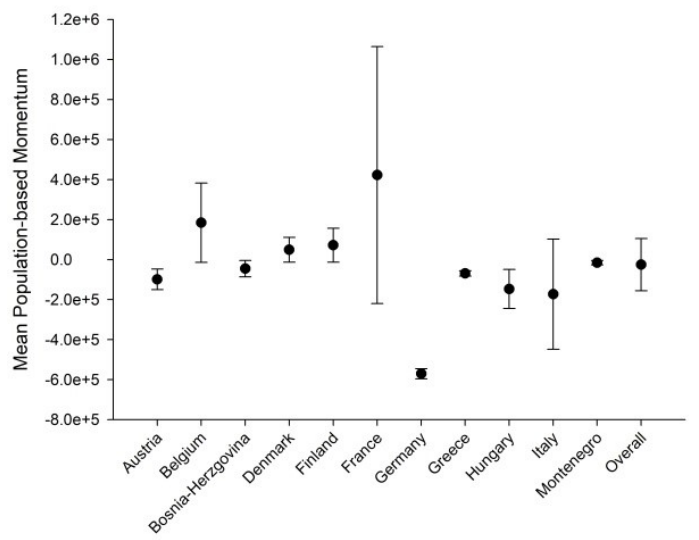

Figure 1. Graphical comparison of the slope (A), internet-user-based momentum (B), and population-based momentum (C) of internet search query data from 2004 - 2018 obtained using Google Trends.

There were no differences in momentum among the countries, whether the volumes of internet users or total populations of the countries were applied (Table 1). Under graphical examination (Fig. 1), Montenegro showed no differences compared to other countries. However, the slope for Germany appeared more negative than most 
European countries, even if this appearance did not demonstrate statistical significance for either calculated momenta. The slopes of the remaining countries were not significantly different from zero.

\section{Discussion}

None of these countries demonstrated particularly strong declining or growing public interest in the environment. However, the results demonstrate how use of slope angle without consideration of population size can be a problem when comparing public interest among different geographical areas. The slopes in internet query data streams provide important information about how the public is shifting its focus among different topics (Askitas and Zimmermann 2009; Nghiem et al. 2016). However, it is mostly a useful element when the investigator is restricting its questions to those focused on regions with very comparable populations. It is also warranted to consider statistical smoothing of data in regions with small populations so that the erratic changes induced by whims do not hide the trajectories of overall public interest, unless of course, whims are the subject of the study. However, comparisons among countries with drastically different populations and/or populations of internet users should be considered carefully. In these cases, ignoring the interaction between trajectory of slope and the size of the population expressing it may hide vitally important information related to how policy has changed and may shift in the future.

Momentum is a term derived from physics that is subject to cavalier use. Like velocity or slope, it is a vector. Therefore, there is directionality in the statistic. But it is more than just how fast the quantity is moving. It also reveals the quantity of movement that is occurring. We know that large quantities in motion are harder to stop than small quantities. In fact, large objects (i.e. mud/landslides, boulders, trucks, etc.) moving down a low slope can be much harder to slow than small objects (i.e. dust, feathers, motor cycles, falling perpendicular to the ground. This principle applies steadfastly to public interest and opinion. We know that large movements in public opinion are much more difficult to counter than small ones. The larger the number of people who believe something, the harder it is to alter that belief. Members of that group regularly reinforce each other's views, cloud the alternative voices, and maintain stability of belief systems. This can be readily observed in politics, religion and even science. Conversely, if few agree it is probable that gaining ground will be very difficult, thus requiring much more effort and financial resources. This is well established in the literature (). Momentum allows us to account for the mass or strength of movement, and predict the effort needed for us to change that trend in perception, view, or belief. Future studies should strongly consider applying momentum to their investigations when comparing different regions so that they can avoid misinterpretations and misperceptions of how public interest influences policy.

\section{Literature Cited}

Ambrus A, Greiner B, Pathak P (2009) Group versus individual decision-making: Is there a shift. Institute for Advanced Study, School of Social Science Economics Working Paper 91.

Andrew L, Arndt D, Beristain N, Cass T, Clow T, Colmenares B, Damm K, Hatcher R, Jackson, Pasquesi W, ChamberlainPham N, Pryde JA, Rund T, Russell G, Ryle C, Schmidt T, Sigan S, Sinkus K, Sneyd K, Strode J, Wallen C, and McCallum ML (2016) Changes in United States' citizens' interest in sustainability (2004 - 2014). Life: The Excitement of Biology 4:138 $-164$.

Askitas N, Zimmermann KF (2009) Google econometrics and unemployment forecasting. Applied Economics Quarterly 55:107 -120 .

Baram-Tsabari A, Segev E (2011) Exploring new web-based tools to identify public interest in science. Public Understanding of Science 20:130 - 143 .

Black L (2012) Stability in a sea of volatility: the predictive power of elite endorsements in the 2012 Republican presidential primary. Dissertation, Boston University.

Brewer MB, Kramer RM (1986) Choice behavior in social dilemmas: Effects of social identity, group size, and decision framing. Journal of Personality and Social Psychology 50:543 - 549.

Carneiro HA, Mylonakis E (2009) Google trends: a web-based tool for real-time surveillance of disease outbreaks. Clinical Infectious Diseases 49:1557 - 1564.

Choi H, Varian H (2012) Predicting the present with Google Trends. Economic Record 88(s1):2-9.

Davis OA, Hinich MJ, Ordeshook PC (1970) An expository development of a mathematical model of the electoral process. American Political Science Review 64:426 - 448.

Dennis AR (1993) Information processing in group decision making: You can lead a group to information, but you can't make it think. Academy of Management Proceedings 1993:283 - 287.

Downs A (1957) An Economic Theory of Democracy. Harper Publishers. New York, NY.

Kulkarni G (2012) Patterns of consumer interest across developed and emerging markets. International Business Economic Research Journal 11:603-610. 
Margetts HZ (2012) The internet and public policy. Policy Internet 1:1 - 21.

McCallum ML, Bury GW (2013) Google search patterns suggest declining interest in the environment. Biodiversity and Conservation 22:1355 - 1367.

McCallum ML, Bury GW (2014) Public interest in the environment is falling: A response to Ficetola (2013). Biodiversity and Conservation 23:1057 - 1062.

McConnell G (1966) Private Power and American Democracy. Random House Publishing. New York, NY.

Mellon J (2013) Where and when can we use Google Trends to measure issue salience? PS: Political Science \& Politics 46:280 290.

Mellon J (2014) Internet search data and issue salience: The properties of Google Trends as a measure of issue salience. Journal of Elections, Public Opinion \& Parties 24:45 - 72.

Monroe BL, Pan J, Roberts ME, Sen M, Sinclair B (2015) No! Formal theory, causal inference, and big data are not contradictory trends in political science. PS: Political Science \& Politics 48:71 - 74.

Newton I (1687) Philosophiæ Naturalis Principia Mathematica. Imprimatur. S. Pepys, Reg. Soc. Presses.

Nghiem LT, Papworth SK, Lim FK, Carrasco LR (2016) Analysis of the capacity of Google Trends to measure interest in conservation topics and the role of online news. PLoS One 11:e0152802.

Page BI, Shapiro RY (1983) Effects of public opinion on policy. The American Political Science Review 77:175 - 190.

Reilly S, Richey S, Taylor JB (2012) Using Google search data for state politics research: An empirical validity test using roll-off data. State Politics Policy Quarterly 12:146 - 159

Ridgeway CL, Balkwell JW (1997) Group processes and diffusion of status beliefs. Social Psychology Quarterly 1997:14 - 31.

Ripberger JT (2011) Capturing curiosity: Using internet search trends to measure public attentiveness. Policy Studies Journal 39:239-259.

Schattschneider EE (1960) The Semi-sovereign People. The Dryden Press. Hinsdale, IL.

Scheitle CP (2011) Google's Insights for Search: A note evaluating the use of search engine data in social research. Social Quarterly 92:285-295.

Schmidt T, Vosen S (2011) Forecasting private consumption: survey-based indicators vs Google Trends. Journal of Forecasting 30:565 - 578.

Seifter A, Schwarzwalder A, Geis K, Aucott J (2010) The utility of Google Trends for epidemiological research: Lyme disease as an example. Geospatial Health 4:135 - 137.

Tindall GW, Shi DE (2016) America: A Narrative History. WW Norton \& Company.

Vayena E, Mastroianni A, Kahn J (2012) Ethical issues in health research with novel online sources. American Journal of Public Health 102:2225-2230.

Yang A (2012) Association of internet search trends with suicide death in Taiwan. European Psychiatry 27(Supplement):1. 
McCallum. Population size and Google Trends. SocARXIV http://osf.io/jc26a

Appendix 1. Data, slopes, and resulting momenta of public interest in seven environmental terms for 11 European countries.

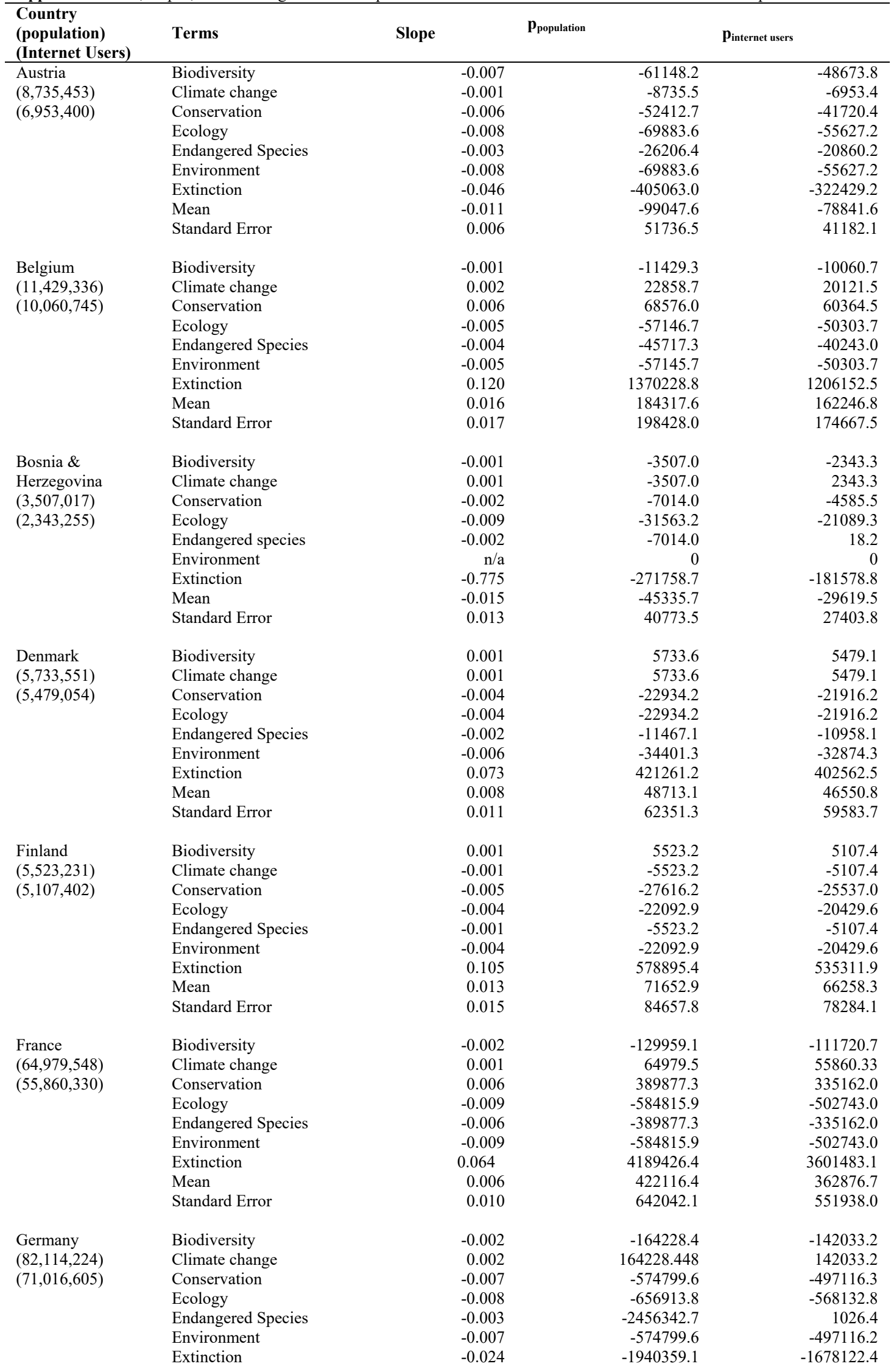


McCallum. Population size and Google Trends. SocARXIV http://osf.io/jc26a

\begin{tabular}{|c|c|c|c|c|}
\hline & Mean & -0.007 & -5790459.2 & -462780.2 \\
\hline & Standard Error & 0.003 & 253263.4 & 227528.6 \\
\hline Greece & Biodiversity & -0.007 & -78118.4 & -49507.7 \\
\hline$(11,159,773)$ & Climate change & -0.007 & -78118.4 & -49507.7 \\
\hline$(7,072,534)$ & Conservation & -0.008 & -89278.2 & -56580.3 \\
\hline & Ecology & -0.009 & -100438.0 & -63652.8 \\
\hline & Endangered species & -0.004 & -44639.1 & -28290.1 \\
\hline & Environment & $\mathrm{n} / \mathrm{a}$ & 0 & 0 \\
\hline & Extinction & -0.009 & -94858.1 & -60116.5 \\
\hline & Mean & -0.007 & -69350.0 & -43950.7 \\
\hline & Standard Error & 0.001 & 13441.3 & 8518.5 \\
\hline Hungary & Biodiversity & -0.006 & -58329.4 & -47248.4 \\
\hline$(9,721,559)$ & Climate change & -0.004 & -38886.2 & -31499.0 \\
\hline$(7,874,733)$ & Conservation & -0.001 & -9721.6 & -7874.7 \\
\hline & Ecology & -0.008 & -77772.5 & -62997.9 \\
\hline & Endangered Species & -0.003 & -29164.7 & -23624.2 \\
\hline & Environment & -0.009 & -87494.0 & -70872.6 \\
\hline & Extinction & -0.075 & -728242.0 & -589896.3 \\
\hline & Mean & -0.015 & -147087.0 & -119145.0 \\
\hline & Standard Error & 0.010 & 97401.6 & 78898.0 \\
\hline Italy & Biodiversity & -0.006 & -356159.4 & -235269.1 \\
\hline$(59,359,900)$ & Climate change & -0.004 & -237439.6 & -156846.1 \\
\hline$(39,211,518)$ & Conservation & -0.009 & -534239.1 & -352903.7 \\
\hline & Ecology & -0.013 & -771678.7 & -509749.7 \\
\hline & Endangered Species & -0.002 & -118719.8 & -78423.0 \\
\hline & Environment & -0.010 & -593599.0 & -392115.2 \\
\hline & Extinction & 0.024 & 1398816 & 924019.4 \\
\hline & Mean & -0.003 & -173289.0 & -114470.0 \\
\hline & Standard Error & 0.005 & 275035.3 & 181680.7 \\
\hline Montenegro & Biodiversity & -0.050 & -12562.7 & -31406.8 \\
\hline$(622,781)$ & Climate Change & $\mathrm{n} / \mathrm{a}$ & 0 & 0 \\
\hline$(249,112)$ & Conservation & $\mathrm{n} / \mathrm{a}$ & 0 & 0 \\
\hline & Ecology & -0.124 & -30992.0 & -77480.2 \\
\hline & Endangered Species & -0.032 & -8046.3 & -20115.8 \\
\hline & Environment & $\mathrm{n} / \mathrm{a}$ & 0 & 0 \\
\hline & Extinction & -0.006 & -1554.5 & -3886.2 \\
\hline & Mean & -0.053 & -7593.7 & -18984.1 \\
\hline & Standard Error & 0.019 & 4314.5 & 10786.4 \\
\hline
\end{tabular}

